\title{
Ethyl Pyruvate Inhibits HMGB1 Phosphorylation and Release by Chelating Calcium
}

\author{
Joo-Hyun Shin, ${ }^{1 *}$ Il-Doo Kim, ${ }^{1 *}$ Seung-Woo Kim, ${ }^{1}$ Hye-Kyung Lee, ${ }^{1}$ Yinchuan Jin, ${ }^{1}$ Ju-Hun Park, ${ }^{2}$ \\ Tae-Kyung Kim, ${ }^{3}$ Chang-Kook Suh, ${ }^{4}$ Jiyeon Kwak, ${ }^{4}$ Keun-Hyeung Lee, ${ }^{2}$ Pyung-Lim Han, ${ }^{3}$ and Ja-Kyeong Lee ${ }^{1}$
}

${ }^{1}$ Department of Anatomy, Inha University School of Medicine, Incheon, Republic of Korea; ${ }^{2}$ Department of Chemistry, and ${ }^{3}$ Department of Brain and Cognitive Science, Ewha Womans University, Seoul, Republic of Korea; and ${ }^{4}$ Department of Physiology and Biophysics, Inha University, Incheon, Republic of Korea

\begin{abstract}
Ethyl pyruvate (EP), a simple aliphatic ester of pyruvic acid, has been shown to have antiinflammatory effects and to confer protective effects in various pathological conditions. Recently, a number of studies have reported EP inhibits high mobility group box 1 (HMGB1) secretion and suggest this might contribute to its antiinflammatory effect. Since EP is used in a calcium-containing balanced salt solution (Ringer solution), we wondered if EP directly chelates $\mathrm{Ca}^{2+}$ and if it is related to the EP-mediated suppression of $\mathrm{HMGB} 1$ release. Calcium imaging assays revealed that EP significantly and dose-dependently suppressed high $\mathrm{K}^{+}$-induced transient $\left(\mathrm{Ca}^{2+}\right)_{i}$ surges in primary cortical neurons and, similarly, fluorometric assays showed that EP directly scavenges Ca ${ }^{2+}$ as the peak of fluorescence emission intensities of Mag-Fura-2 (a low-affinity $\mathrm{Ca}^{2+}$ indicator) was shifted in the presence of EP at concentrations of $\geq 7 \mathrm{mmol} / \mathrm{L}$. Furthermore, EP markedly suppressed the A23187-induced intracellular $\mathrm{Ca}^{2+}$ surge in BV2 cells and, under this condition, A23187-induced activations of $\mathrm{Ca}^{2+}$-mediated kinases (protein kinase $\mathrm{C} \alpha$ and calcium/calmodulin-dependent protein kinase IV), HMGB1 phosphorylation and subsequent secretion of HMGB1 also were suppressed. (A23187 is a calcium ionophore and BV2 cells are a microglia cell line.) Moreover, the above-mentioned EP-mediated effects were obtained independent of cell death or survival, which suggests that they are direct effects of EP. Together, these results indicate that EP directly chelates Ca ${ }^{2+}$, and that it is, at least in part, responsible for the suppression of HMGB1 release by EP.
\end{abstract}

Online address: http://www.molmed.org

doi: $10.2119 / \mathrm{molmed} .2014 .00039$

\section{INTRODUCTION}

Ethyl pyruvate (EP) is a simple aliphatic ester of pyruvic acid and has been shown to confer protective effects in various disease models. For example, EP administration improved survival in lethal models of hemorrhagic shock and diminished ischemia-induced myocardial injury $(1,2)$. EP also significantly reduced infarct volumes in the postischemic brain (3) and attenuated kainic acid-induced neuronal cell death in the
CA1 and CA3 regions of the mouse hippocampus (4). In addition, EP has been reported to attenuate experimental severe acute pancreatitis (5) and to improve motor function scores in models of spinal cord ischemia and traumatic brain injury $(6,7)$.

The protective effects of EP have been attributed to its antiinflammatory, antioxidative and antiapoptotic effects. Regarding its antiinflammatory effects, various molecular mechanisms have been sug-

*J-H Shin and I-D Kim contributed equally to this work.

Address correspondence to Ja-Kyeong Lee, Department of Anatomy, Inha University School of Medicine, Jung-Gu Shinheung-Dong Third St. 7-241, Incheon, 400-712, Republic of Korea. Phone: + 82-32-890-0913; Fax: + 82-32-884-2105; E-mail: jklee@inha.ac.kr. Submitted March 1, 2014; Accepted for publication October 13, 2014; Epub (www.molmed.org) ahead of print October 13, 2014.

\section{The Feinstein Institute for Medical Research Empowering Imagination. Pioneering Discovery.}

gested. Inhibition of the DNA binding of p65 (a nuclear factor [NF]-кB subunit) by EP via decreasing intracellular glutathione (GSH) levels has been reported (8), which results in changing the intracellular redox conditions to favor the oxidation of the key cysteine residue in p65. Covalent modification of $\mathrm{p} 65$ by EP also has been reported (9). EP not only suppresses proinflammatory cytokine production via NF- $\kappa$ B inhibition $(10,11)$ but also was found to increase the production of antiinflammatory cytokines in lipopolysaccharide (LPS)-injected- rat model and ischemic rat model $(1,3)$. Furthermore, it has been reported that the antiinflammatory effect of EP is attributable to the inhibition of reactive oxygen species (ROS)-dependent signal transducer and activator of transcription (STAT) signaling (12). In addition, we recently reported that EP induced p300 sequestration by Nrf2-suppressed p65 activation (13), which suggests a link exists 
between the antiinflammatory and antioxidative functions of EP.

A number of reports have demonstrated that EP inhibits HMGB1 secretion and that this contributes to its antiinflammatory effects (14-18). HMGB1 is an endogenous danger signal molecule and extracellular HMGB1 induces the secretions of various proinflammatory cytokines and aggravates inflammatory processes $(19,20)$. The secretory mechanism involved has been investigated (21) and has shown that serine phosphorylation of HMGB1 is essential for its translocation from the nucleus to cytoplasm. Furthermore, the activations of two calcium-mediated protein kinases, that is, classical protein kinase $\mathrm{C}(\mathrm{cPKC})$ and calcium/calmodulin-dependent protein kinase type IV (CaMKIV), have been reported to play critical roles in the phosphorylation of HMGB1 $(22,23)$.

$\mathrm{EP}$ is used in a $\mathrm{Ca}^{2+}$-containing balanced salt solution (Ringer-EP solution), in which two molecules of EP associate with $\mathrm{Ca}^{2+}$. In the present study, we examined whether EP directly chelates $\mathrm{Ca}^{2+}$, and whether this chelation is responsible for the EP-mediated suppression of HMGB1 release.

\section{MATERIALS AND METHODS}

\section{EP Treatment}

EP (Sigma-Aldrich, St. Louis, MO, USA) was added to Ringer solution, which contained sodium (130 mmol/L), potassium (4 mmol/L), calcium (2.7 mmol/L) and chloride (139 mmol/L) ( $\mathrm{pH} 7.0)$. BV2 cells were treated with 1 , 2.5 or $5 \mathrm{mmol} / \mathrm{L}$ of EP for $30 \mathrm{~min}$ or $1 \mathrm{~h}$. For A23187 (Sigma-Aldrich) treatment, cells were cotreated with $1,2.5$ or $5 \mu \mathrm{mol} / \mathrm{L}$ of A23187 and EP (2.5 or $5 \mathrm{mmol} / \mathrm{L})$ or ethylene glycol tetraacetic acid (EGTA) $(0.25,0.5$ or $1 \mathrm{mmol} / \mathrm{L})$ (Calbiochem [EMD Millipore, Billerica, MA, USA]) for $30 \mathrm{~min}$ or pretreated with 5,10 or $20 \mu \mathrm{mol} / \mathrm{L}$ of $1,2-\mathrm{Bis}(2-$ aminophenoxy)ethane- $\mathrm{N}, \mathrm{N}, \mathrm{N}^{\prime}, \mathrm{N}^{\prime}-$ tetraacetic acid acetoxymethyl ester (BAPTA) (Calbiochem [EMD Millipore]) for 30 min prior to A23187 treatment.

\section{Cell Cultures}

BV2 and RAW264.7 cells were grown in Dulbecco's modified Eagle medium (DMEM) (Hyclone, Logan, UT, USA) supplemented with $5 \%$ fetal bovine serum (FBS) (Gibco [Thermo Fisher Scientific, Waltham, MA, USA]) and 1\% penicillin/streptomycin.

\section{Primary Cortical Cultures}

Experiments were carried out in strict accordance with the recommendations made in the Guide for the Care and Use of Laboratory Animals published by the National Institute of Health (24). The animal protocol used in this study was reviewed and approved by the INHA UniversityInstitutional Animal Care and Use Committee (INHA-IACUC) with respect to ethicality (approval number INHA130607-209). Primary cortical cultures were prepared from embryonic d-15.5 mouse cortices and cultured as described previously (25). For N-methyl-D-aspartic acid (NMDA) treatment (Sigma-Aldrich), cells were pretreated with BAPTA $(5,10$ or $20 \mu \mathrm{mol} / \mathrm{L})$ for $30 \mathrm{~min}$ prior to NMDA treatment $(100 \mu \mathrm{mol} / \mathrm{L}, 10 \mathrm{~min}$ or $50 \mu \mathrm{mol} / \mathrm{L}, 30 \mathrm{~min})$ or cotreated with $\operatorname{EP}(5,10$ or $15 \mathrm{mmol} / \mathrm{L})$ or EGTA $(0.5$, 1 or $2 \mathrm{mmol} / \mathrm{L}$ ) and NMDA for $10 \mathrm{~min}$ or $30 \mathrm{~min}$, respectively. For $\mathrm{Ca}^{2+}$ imaging experiment, dissociated cortical cells were plated at a density of approximately $4 \times$ $10^{5}$ cells per well using 24 -well plate containing single 12-mm cover glass (Deckglasser, Mulheim, Germany) coated with poly-D-lysine, and grown until $20 \%$ to $30 \%$ confluent.

\section{$\mathrm{Ca}^{2+}$ Imaging}

Dissociated primary cortical neurons were loaded with $10 \mu \mathrm{mol} / \mathrm{L}$ Mag-Fura-2 (Molecular Probes [Thermo Fisher Scientific]) in Tyrode solution $(140 \mathrm{mmol} / \mathrm{L}$ $\mathrm{NaCl}, 2.5 \mathrm{mmol} / \mathrm{L} \mathrm{CaCl}_{2}, 5 \mathrm{mmol} / \mathrm{L} \mathrm{KCl}$, $1 \mathrm{mmol} / \mathrm{L} \mathrm{MgCl}_{2}, 1 \mathrm{mmol} / \mathrm{L} \mathrm{NaH}_{2} \mathrm{PO}_{4}$ $5 \mathrm{mmol} / \mathrm{L}$ 4-(2-hydroxyethyl)-1piperazineethanesulfonic acid (HEPES) and $5.5 \mathrm{mmol} / \mathrm{L}$ glucose [pH 7.4]) supplemented with $0.02 \%$ Pluronic acid (Molecular Probes [Thermo Fisher Scientific]) at $37^{\circ} \mathrm{C}$. One hour after dye loading, cells were washed three times for $30 \mathrm{~min}$ each to allow deesterification of the acetoxymethyl ester. Cells were viewed under a Nikon Diapot microscope (DIAPOT-300) (Nikon Corporation, Tokyo, Japan) attached with a CCD camera (PXL-37) (Photometrics, Tucson, AZ, USA). Light was generated using a xenon lamp and filtered through 340- or 380-nm filters. Fluorescence intensities were measured using a 510-nm filter using a cooled CCD digital camera (PXL-37) (Photometrics). Ratios of fluorescence intensities of Mag-fura-2 excited at 340 and $380 \mathrm{~nm}\left(\right.$ Ratio $\left._{340 / 380}\right)$ were obtained using Axon imaging workbench 2.2 (Axon Instruments, Union City, CA, USA) and used as surrogates of $\left[\mathrm{Ca}^{2+}\right]_{i}$. Primary cortical neurons were treated with $30 \mathrm{mmol} / \mathrm{L} \mathrm{K}^{+}$using a pressure application system (Pressure System IIe; Toohey Company, Fairfield, NJ, USA) at 20 pounds per square inch (psi) and 100 -ms pulse duration. Ratio ${ }_{340 / 380}$ values were recorded every $2 \mathrm{~s}$. All imaging experiments were performed in the dark at room temperature.

\section{Preparation of Cell Extracts and Protein Contents in Media}

Nuclear and cytosolic extracts were prepared using NE-PER nuclear and cytoplasmic extraction reagents (Thermo Fisher Scientific), according to the manufacturer's instructions. To prepare protein from culture media, media were centrifuged at $500 \mathrm{~g}$ for $5 \mathrm{~min}$ to remove cellular debris. Supernatants were collected and concentrated using a Nanosep centrifugal device (Pall Life Sciences, Ann Arbor, MI, USA), according to the manufacturer's instructions.

\section{Immunoblotting}

Cells were washed twice with cold phosphate-buffered saline (PBS) and lysed using radioimmunoprecipitation assay (RIPA) buffer (50 mmol/L Tris- $\mathrm{HCl}$ (pH 7.4), 1\% NP40, 0.25\% sodium-deoxycholate, $150 \mathrm{mmol} / \mathrm{L} \mathrm{NaCL}, 1 \mathrm{mmol} / \mathrm{L}$ $\mathrm{Na}_{3} \mathrm{VO}_{4}$ and one mini-protease inhibitor cocktail tablet (Roche Diagnostics, Mannheim, Germany). Lysates were centrifuged at $14,000 \mathrm{~g}$ for $15 \mathrm{~min}$ at $4^{\circ} \mathrm{C}$ and 
supernatants were then loaded onto $12 \%$ SDS-PAGE gels. The primary antibodies (diluted at 1:1000) used were as follows: anti-HMGB1 (ab67281) (Abcam, Cambridge, MA, USA) for cerebrospinal fluid (CSF) and media, anti-HMGB1 from (sc56698) (Santa Cruz Biotechnology, Santa Cruz, CA, USA) for lysates, anti-inducible nitric oxide synthase (anti-iNOS)

(Abcam), anti-PKC $\alpha$ (BD Biosciences, San Jose, CA, USA), anti-CaMKIV (BD Biosciences), anti-p62 (Santa Cruz Biotechnology), anti-lamin B (Santa Cruz Biotechnology), and anti- $\alpha$-tubulin (Calbiochem [EMD Millipore]). Primary antibodies were detected using BM Chemiluminescence Blotting Substrate (Roche Diagnostics) and goat anti-rabbit, goat antimouse, and donkey anti-goat horseradish peroxidase-conjugated secondary antibodies (Millipore Bioscience Research Reagents, Temecula, CA, USA) were used.

\section{Coimmunoprecipitation-Linked Immunoblotting}

Total lysates containing $500 \mu \mathrm{g}$ of protein were immunoprecipitated with $2 \mu \mathrm{L}$ of anti-HMGB1 antibody (Abcam) overnight at $4^{\circ} \mathrm{C}$. Preequilibrated protein $\mathrm{G}$ PLUS-Agarose beads (Santa Cruz Biotechnology) were then added and incubated for $2 \mathrm{~h}$ at $4^{\circ} \mathrm{C}$ on a rotating wheel. Beads were washed three times with RIPA buffer and the proteins so obtained were separated by SDS-PAGE. Anti-phospho-serine antibody (Millipore Bioscience Research Reagents) was used as the primary antibody at a dilution of 1:1000.

\section{Cell Viabilities and NO Measurements}

Cell viabilities after A23187 (a calcium ionophore) (Sigma-Aldrich) treatment (1, 2.5 or $5 \mu \mathrm{mol} / \mathrm{L}$ ) were analyzed using the MTT (3-[4,5-dimethylthiaziazol-3-yl] 2,5diphenyl tetrazolium bromide) method. Briefly, $24 \mathrm{~h}$ after A23187 treatment (1, 2.5 or $5 \mu \mathrm{mol} / \mathrm{L}, 30 \mathrm{~min})$, cells were stained with $500 \mu \mathrm{g} / \mathrm{mL}$ MTT (Sigma-Aldrich). Media were then carefully aspirated and $200 \mu \mathrm{L}$ of dimethyl sulfoxide (DMSO) was added to solubilize the colored formazan product. Optical densities were read at $550 \mathrm{~nm}$. For lactate dehydrogenase (LDH) assay, $50 \mu \mathrm{L}$ of A23187-treated media were mixed with same volume of LDH assay reagent (Roche Diagnostics) in a 96-well plate and incubated for $15 \mathrm{~min}$. Optical densities were read at $490 \mathrm{~nm}$. To measure the amount of NO produced by BV2 cells, $100 \mu \mathrm{L}$ of conditioned medium was mixed with an equal volume of Griess reagent (0.5\% sulfanilamide and $0.05 \% \mathrm{~N}-1$ naphthylethylenediamine), and incubated for $10 \mathrm{~min}$ at room temperature. Absorbance of the mixture at $550 \mathrm{~nm}$ was measured using a microplate reader (BioTek Instruments Inc., Winooski, VT, USA).

\section{Calcium Assay and Staining}

BV2 cells were treated with $2.5 \mu \mathrm{mol} / \mathrm{L}$ of A23187 for $30 \mathrm{~min}$ and then incubated with $4 \mu \mathrm{mol} / \mathrm{L}$ of Flou-4 (Molecular Probes [Thermo Fisher Scientific]) for $30 \mathrm{~min}$ and rinsed twice with PBS Increased fluorescence excitation at $488 \mathrm{~nm}$ was determined by confocal microscopy (LSM 510 META) (Carl Zeiss MicroImaging Inc., Thornwood, NY, USA) and by using a fluorescence microplate reader (Luminmax-c luminometer; Maxwell Sensors Inc., Santa Fe Springs, CA, USA).

\section{Measurement of $\mathrm{Ca}^{2+}$ Chelating Activity}

Excitation spectra of mag-fura-2

$(10 \mu \mathrm{mol} / \mathrm{L})$ (Molecular Probes [Thermo Fisher Scientific]) in the presence of various concentration of $\mathrm{CaCl}_{2}$ were measured in aqueous buffered solution (10 mmol/L MOPS, $120 \mathrm{mmol} / \mathrm{L} \mathrm{KCl}$, $\mathrm{pH}$ 7.15) using a LS55 Luminescence spectrometer (PerkinElmer Inc, Waltham, MA, USA). Fluorescence excitation spectra of mag-Fura-2 $(10 \mu \mathrm{mol} / \mathrm{L})$ and $\mathrm{CaCl}_{2}$ ( $1 \mathrm{mmol} / \mathrm{L})$ were measured in the same buffered solution in the presence of ethylenediaminetetraacetic acid (EDTA), EP and sodium pyruvate, respectively. Fluorescent excitation spectra detected at 510 nm were measured at $22^{\circ} \mathrm{C}$ and the slit widths for excitation and emission were 15 and $20 \mathrm{~nm}$, respectively. Fluorescence excitation spectra were recorded from $250 \mathrm{~nm}$ to $450 \mathrm{~nm}$ (increment $0.5 \mathrm{~nm}$ ). Data analysis was performed using FL WinLab software (PerkinElmer Inc).

\section{Statistical Analysis}

Two-sample comparisons were performed using the Student $t$ test, while multiple comparisons were made using one-way or two-way analysis of variance (ANOVA) followed by post hoc test to compare selected pairs of data. PRISM software 5.0 (GraphPad Software Inc., La Jolla, CA, USA) was used to perform statistical analysis. All data are presented as mean \pm SEM and statistical difference was accepted at the 5\% level.

\section{RESULTS}

\section{EP Decreased $\mathrm{K}^{+}$-Induced $\left(\mathrm{Ca}^{2+}\right)_{\mathrm{i}}$ Increases in Primary Cortical Neurons}

To investigate whether EP affects intracellular $\mathrm{Ca}^{2+}$ concentration $\left(\left[\mathrm{Ca}^{2+}\right]_{\mathrm{i}}\right)$, we measured paired responses on the high $\mathrm{K}^{+}$-induced transient $\left[\mathrm{Ca}^{2+}\right]_{\mathrm{i}}$ increases. $\mathrm{Ca}^{2+}$ influxes were evoked in isolated primary cortical neurons by $30 \mathrm{mmol} / \mathrm{L}$ of $\mathrm{K}^{+}$-containing normal Tyrode solution and ratios of fluorescence intensities of Mag-fura-2 excited at 340 and $380 \mathrm{~nm}$ $\left(\right.$ Ratio $\left._{340 / 380}\right)$ were used as surrogates of $\left[\mathrm{Ca}^{2+}\right]_{\mathrm{i}}$. When $\mathrm{K}^{+}(30 \mathrm{mmol} / \mathrm{L})$ was applied for $10 \mathrm{~s}$, transient $\mathrm{Ca}^{2+}$ responses were evoked (Ratio $_{340 / 380} ; 0.47 \pm 0.04, \mathrm{n}=$ 29 cells) (Figure 1A). After primary cortical neurons were superfused with the Tyrode solution for $5 \mathrm{~min}$ to wash out the initial $\mathrm{K}^{+}$, $30 \mathrm{mmol} / \mathrm{L}$ of $\mathrm{K}^{+}$was reapplied to the same cells. This second high $\mathrm{K}^{+}$application elicited transient $\mathrm{Ca}^{2+}$ responses similar to the first application $\left(\right.$ Ratio $_{340 / 380} ; 0.47 \pm 0.03 ; \mathrm{n}=29$ cells) (see Figure 1A). However, if EP (5 mmol/L) was treated for $3 \mathrm{~min}$ before second high $\mathrm{K}^{+}$application (bold bar in Figure $1 \mathrm{~B}$ ), second $\mathrm{K}^{+}$-induced $\left[\mathrm{Ca}^{2+}\right]_{\mathrm{i}}$ increases were significantly suppressed as compared with first $\mathrm{K}^{+}$-induced responses, $41.4 \pm$ $1.9 \%$ of the first response ( $\mathrm{n}=60$ cells, ${ }^{* *} p<0.01$ ) (Figure 1B). Furthermore, 0.5 or $1 \mathrm{mmol} / \mathrm{L}$ of EP suppressed high $\mathrm{K}^{+}$induced $\left[\mathrm{Ca}^{2+}\right]_{\mathrm{i}}$ increase to $66.4 \pm 2.5 \%$ ( $\mathrm{n}=44$ cells, ${ }^{* *} p<0.01$ ) or $56.0 \pm 2.0 \%$ ( $\mathrm{n}=50$ cells, $\left.{ }^{* *} p<0.01\right)$ of the first response, respectively, indicating that EP suppressed $\left[\mathrm{Ca}^{2+}\right]_{\mathrm{i}}$ in a dose-dependent manner (Figure 1C). 

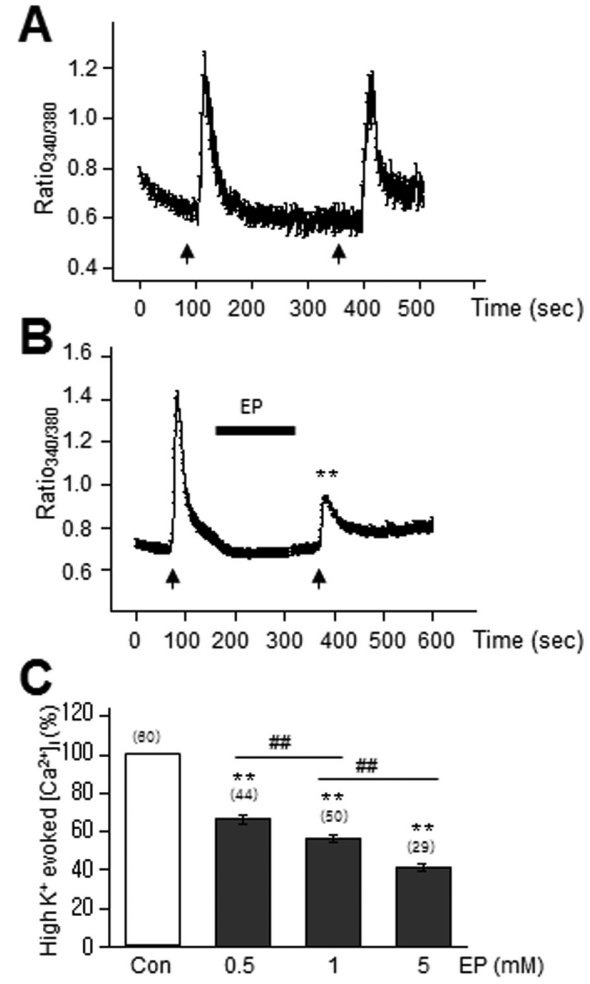

Figure 1. Effects of EP on high $\mathrm{K}^{+}$-induced $\left(\mathrm{Ca}^{2+}\right)_{\text {i }}$ increase in primary cortical neurons. (A) Paired transient $\mathrm{Ca}^{2+}$ responses of isolated primary cortical neurons were evoked by repetitive applications of high $\mathrm{K}^{+}$. Intracellular $\mathrm{Ca}^{2+}$ concentrations were presented as fluorescence ratios at $340 / 380 \mathrm{~nm}$. High $\mathrm{K}^{+}$(30 mmol/L) was applied for $10 \mathrm{~s}$ at the time indicated by arrows and it was followed by 5 min superfusion with Tyroid's solution to wash out the initial $\mathrm{K}^{+}$before the second $\mathrm{K}^{+}(30 \mathrm{mmol} / \mathrm{L})$ application $(\mathrm{n}=29)$. (B) Paired transient $\mathrm{Ca}^{2+}$ responses were measured after treating EP ( $5 \mathrm{mmol} / \mathrm{L})$ for 3 min (bold line) before the second $\mathrm{K}^{+}$ (30 $\mathrm{mmol} / \mathrm{L})$ application $(\mathrm{n}=60)$. (C) Effects of EP $(0.5,1$, or $5 \mathrm{mmol} / \mathrm{L})$ on high $\mathrm{K}^{+}$-evoked transients $\mathrm{Ca}^{2+}$ responses were measured. Results are presented as mean \pm SEM and values at the top of each bar represent the number of cells. One-way ANOVA, Newman-Keuls post hoc test. ${ }^{* *}$, difference from Con at $p<0.01 ; "$, differences between indicated group at $p<0.01$.

\section{EP Directly Scavenged $\mathrm{Ca}^{2+}$ under Cell Free Conditions}

To further confirm that EP directly chelates $\mathrm{Ca}^{2+}$, fluorescence spectra stud-
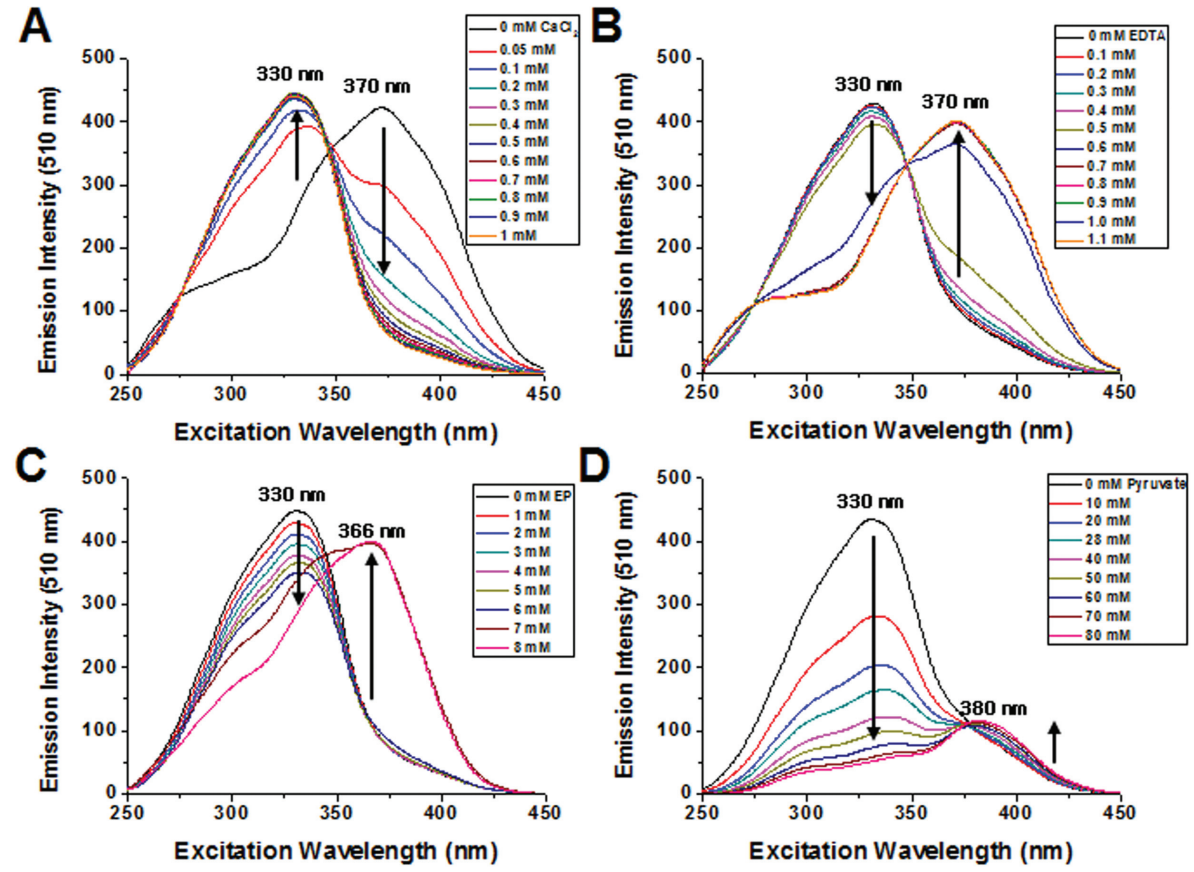

Figure 2. Excitation spectra of mag-fura-2 in the presence of $\mathrm{Ca}^{2+}$ or EP. (A) Excitation spectra of mag-fura-2 $(10 \mu \mathrm{mol} / \mathrm{L})$ were measured in the presence of $\mathrm{CaCl}_{2}$. Excitation spectra of mag-fura-2 $(10 \mu \mathrm{mol} / \mathrm{L})$ with $\mathrm{CaCl}_{2}(1 \mathrm{mmol} / \mathrm{L})$ were measured in the presence of $(\mathrm{B})$ EDTA, (C) EP, and (D) sodium pyruvate under cell free conditions by spectrofluorometer. The excitation spectrum detected at $510 \mathrm{~nm}$ was collected $\left(\gamma_{\mathrm{em}}=510 \mathrm{~nm}\right.$, Slit $\left.=15 / 20 \mathrm{~nm}, 1 \% \mathrm{~T}\right)$.

ies were conducted with mag-Fura-2 (low affinity $\mathrm{Ca}^{2+}$ indicator). We first carried out the titration experiment of mag-fura-2 with $\mathrm{CaCl}_{2}$. As shown in Figure $2 \mathrm{~A}$, about $1 \mathrm{mmol} / \mathrm{L} \mathrm{CaCl}_{2}$ was enough to completely form the complex between mag-fura-2 $(10 \mu \mathrm{mol} / \mathrm{L})$ and $\mathrm{Ca}^{2+}$ because the band at $370 \mathrm{~nm}$ corresponding to free mag-fura-2 decreased and the band at $330 \mathrm{~nm}$ corresponding to the complex increased. To confirm the chelating activity of EP for $\mathrm{Ca}^{2+}$, fluorescence excitation spectra of mag-Fura-2 $(10 \mu \mathrm{mol} / \mathrm{L})$ and $\mathrm{CaCl}_{2}(1 \mathrm{mmol} / \mathrm{L})$ were compared in the presence of EDTA, EP or sodium pyruvate. The addition of increasing amounts of EDTA as a wellknown $\mathrm{Ca}^{2+}$-chelating agent induced an increase of the band at $370 \mathrm{~nm}$ as well as a decrease of the band $330 \mathrm{~nm}$, which indicated that EDTA removed calcium ions from mag-fura-2, resulting in the same spectrum of mag-fura- 2 in the absence of $\mathrm{Ca}^{2+}$ (Figures 2A, B). Upon addition of an increasing amount of EP into the solution containing mag-fura- 2 and $\mathrm{CaCl}_{2}$, the band at $330 \mathrm{~nm}$ decreased and the band at $367 \mathrm{~nm}$ increased at the concentration higher than $7 \mathrm{mmol} / \mathrm{L}$ (Figure 2C). This result suggests that EP, like EDTA, acts as a chelating agent, removing calcium ions from mag-fura-2. The chelating activity of EP was weaker than that of EDTA for $\mathrm{Ca}^{2+}$ because almost 9-fold excess of EP fully removed $\mathrm{Ca}^{2+}$ from mag-fura-2. However, upon addition of an increasing amount of sodium pyruvate into the solution containing mag-fura- 2 and $\mathrm{CaCl}_{2}$, the band at $330 \mathrm{~nm}$ decreased but the band at $370 \mathrm{~nm}$ corresponding to free mag-fura-2 did not increase (Figure 2D), which suggested that pyruvate did not remove $\mathrm{Ca}^{2+}$ from mag-fura-2. To investigate whether the decrease of the intensity at $330 \mathrm{~nm}$ may be due to the absorbance by pyruvate, excitation spectra of mag-fura2 in the presence of sodium pyruvate without $\mathrm{CaCl}_{2}$ were measured. The final spectrum of mag-fura-2 was almost the 


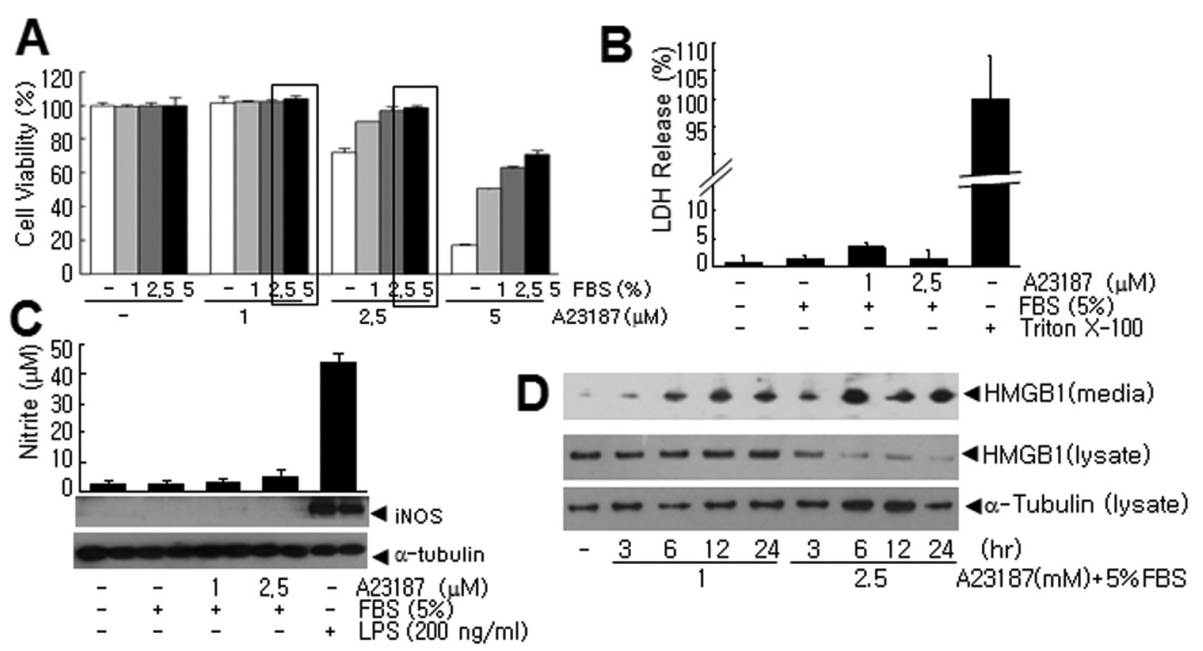

Figure 3. A23187-induced HMGB1 secretion in the absence of cell death. (A) Cell viabilities were determined using a MTT assay $24 \mathrm{~h}$ after $30 \mathrm{~min}$ of $\mathrm{A} 23187(1,2.5$ or $5 \mu \mathrm{mol} / \mathrm{L})$ treatment in the presence of $1 \%, 2.5 \%$ or $5 \%$ of FBS. Results are presented as means \pm SEMs $(n=3)$. (B-C) BV2 cells were treated with 1 or $2.5 \mu \mathrm{mol} / \mathrm{L}$ of $A 23187$ in the presence of $5 \% \mathrm{FBS}$ for $30 \mathrm{~min}$ and (B) LDH release, (C) nitrite production and (C) iNOS expression were measured $24 \mathrm{~h}$ later. Results are presented as means \pm SEMs $(n=4)$. (D) BV2 cells were treated with 1 or $2.5 \mu \mathrm{mol} / \mathrm{L}$ of $\mathrm{A} 23187$ in the presence of $5 \% \mathrm{FBS}$ for 30 min and $\mathrm{HMGB} 1$ levels in culture media and in cell lysates were estimated by immunoblotting at 3 , 6, 12 and $24 \mathrm{~h}$ after A23187 treatment.

same as that of mag-fura-2 in the presence of sodium pyruvate with $\mathrm{CaCl}_{2}$ (1 mmol/L) (Supplementary Figure S1), which confirmed that the decrease of the intensity at $330 \mathrm{~nm}$ was due to the absorbance of a high concentration of pyruvate.

\section{A23187 Induced HMGB1 Secretion in BV2 Cells Without Causing Concomitant Activation or Cell Death}

Recently, we reported that EP inhibits HMGB1 release in the postischemic brain and in BV2 cells (a microglia cell line) $(18,24)$. In addition, we also showed that EP suppressed PKC $\alpha$ - or CaMKIVmediated HMGB1 phosphorylation in BV2 cells (18). Efficient $\mathrm{Ca}^{2+}$ chelation by EP prompted us to investigate the possibility that the inhibition of HMGB1 release by EP is due to the suppression of the $\mathrm{Ca}^{2+}$-induced activations of $P K C \alpha$ and $C a M K I V$. To find a culture condition that triggered HMGB1 secretion from BV2 cells without causing cell death, BV2 cells were cultured in media containing $\mathrm{Ca}^{2+}$ ionophore (A23187; 1, 2.5 or
$5 \mu \mathrm{mol} / \mathrm{L})$ for $30 \mathrm{~min}$ in the presence of FBS $(1 \%, 2.5 \%$ or $5 \%)$ and cell viabilities were examined $24 \mathrm{~h}$ later (Figure 3A). In the presence of 5\% FBS, cell viabilities were maintained at $100 \%$ even when they were treated with 1 or $2.5 \mu \mathrm{mol} / \mathrm{L}$ of A23187 ( $n=4)$ (see Figure 3A). Complete survival and no activation of BV2 cells were confirmed by LDH (Figure 3B) and NO assays (Figure $3 \mathrm{C}$ ), respectively. No activation of BV2 cells was further confirmed by showing that iNOS (see Figure 3C) and proinflammatory marker expressions (Supplementary Figure S2) were also not changed after 1 or $2.5 \mu \mathrm{mol} / \mathrm{L}$ of A23187 treatment. However, under these conditions, HMGB1 secretion was detected at $3 \mathrm{~h}$ after A23187 treatment and HMGB1 continuously accumulated in culture media until $24 \mathrm{~h}$ with a concomitant decrease of HMGB1 in cell lysate (Figure 3D). These results indicate that treatment with 1 or $2.5 \mu \mathrm{mol} / \mathrm{L}$ of A23187 induced HMGB1 secretion from BV2 cells by increasing $\left[\mathrm{Ca}^{2+}\right]_{\mathrm{i}}$ without causing concomitant cell death or activation.

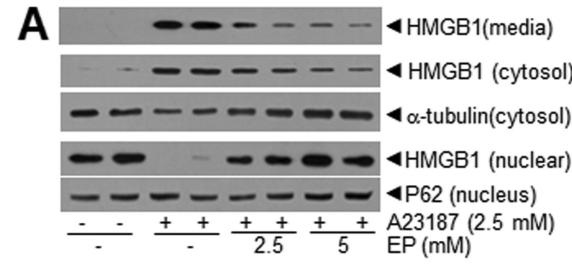

B

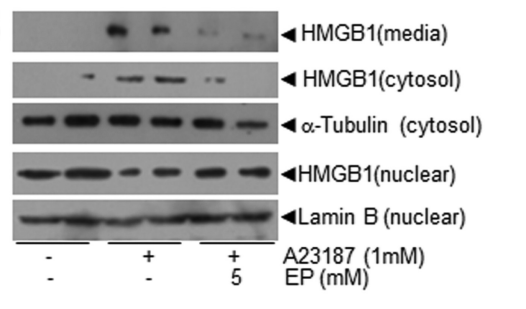

Figure 4. Inhibition of A23187-induced HMGB1 secretion by EP. (A) BV2 cells were incubated with A23187 ( $2.5 \mu \mathrm{mol} / \mathrm{L}$ ) and 2.5 or $5 \mathrm{mmol} / \mathrm{L}$ of EP for $30 \mathrm{~min}$ and HMGB1 levels in culture media, cytoplasm, and nuclei were estimated by immunoblotting at $24 \mathrm{~h}$ after A23187 treatment. Immunoblots obtained using anti- $\alpha$ tubulin or anti-p62 antibodies were used as controls for cytosolic and nuclear fractions, respectively. (B) Similar experiments were carried out in RAW264.7 mouse macrophage cells using $5 \mathrm{mmol} / \mathrm{L}$ of EP.

\section{EP Blocked A23187-induced HMGB 1 Secretion at the Level of Nuclear-to- Cytoplasmic Translocation}

To determine whether EP inhibits A23187-induced HMGB1 secretion, BV2 cells were cotreated with 2.5 or $5 \mathrm{mmol} / \mathrm{L}$ of EP and A23187 (2.5 $\mu \mathrm{mol} / \mathrm{L})$ for $30 \mathrm{~min}$ and levels of HMGB1 in media, nuclear and cytoplasmic fractions were examined $24 \mathrm{~h}$ later. EP significantly blocked HMGB1 secretion at the level of nuclear-to-cytoplasmic translocation (Figure 4A). Similar inhibition of A23187-induced HMGB1 secretion by EP was also observed in RAW264.7 cells (Figure 4B). Together, these results indicate EP inhibits A23187-induced HMGB1 secretion at the level of nuclear to cytoplasmic translocation.

\section{EP Suppressed A23187-Induced Intracellular $\mathrm{Ca}^{2+}$ Increases in BV2 Cells}

To examine whether EP suppresses A23187-induced intracellular $\mathrm{Ca}^{2+}$ increase 

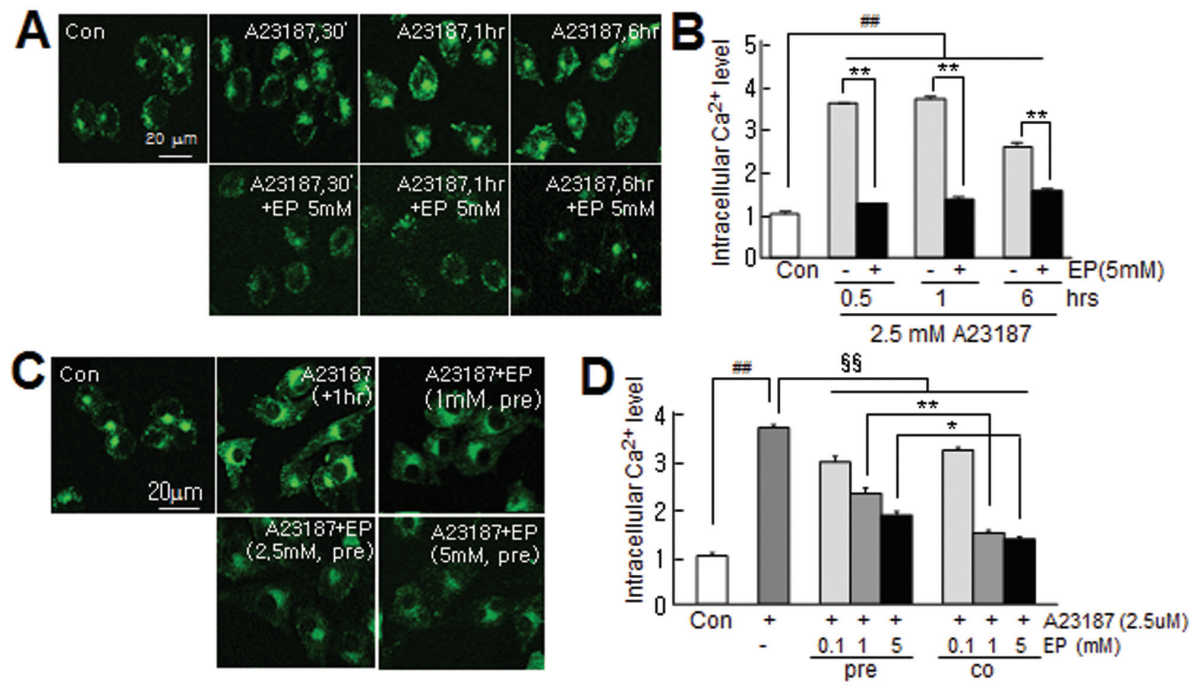

Figure 5. Reduction of A23187-induced intracellular calcium influx by EP in BV2 cells. $(A, B)$ Intracellular $\mathrm{Ca}^{2+}$ levels at $30 \mathrm{~min}, 60 \mathrm{~min}$ and $6 \mathrm{~h}$ after $\mathrm{A} 23187$ treatment $(2.5 \mu \mathrm{mol} / \mathrm{L}$, $30 \mathrm{~min}$ ) in the presence or absence of $5 \mathrm{mmol} / \mathrm{L}$ EP were visualized by (A) confocal microscopy and were measured using a (B) fluorescent microplate reader. (C,D) BV2 cells were either co- or pretreated with EP and intracellular $\mathrm{Ca}^{2+}$ levels were measured. For pretreatment, BV2 cells were treated with 1, 2.5 or $5 \mathrm{mmol} / \mathrm{L}$ EP for $1 \mathrm{~h}$. Media were then replaced with fresh DMEM containing A23187 (2.5 $\mathrm{mmol} / \mathrm{L})$ and incubated for $30 \mathrm{~min}$. Intracellular $\mathrm{Ca}^{2+}$ levels at $1 \mathrm{~h}$ after EP treatment were visualized by (C) confocal microscopy and were measured using a (D) fluorescence microplate reader. (A,C) Representative images from four independent experiments are presented and data are presented as mean $\pm \operatorname{SEM}(n=12)$. One-way ANOVA, Newman-Keuls post hoc test. "\#, difference from Con at $p<0.01$; $\$$, difference from A23187-treated group at $p<0.01$; * and ${ }^{* *}$, differences between indicated group at $p<0.05$ and $p<0.01$, respectively. Scale bar, $20 \mu \mathrm{m}$.

in BV2 cells, intracellular $\mathrm{Ca}^{2+}$ levels were examined in the presence or absence of EP using Fluo-4, a fluorescent $\mathrm{Ca}^{2+}$ indicator. After treating BV2 cells with A23187 (2.5 $\mu \mathrm{mol} / \mathrm{L}, 30 \mathrm{~min})$, intracellular Fluo-4-positive fluorescence level was increased markedly at $30 \mathrm{~min}$, maintained at $1 \mathrm{~h}$ and decreased slightly at $6 \mathrm{~h}$ (Figures 5A, B). However, A23187-induced Flou-4 signals were reduced by cotreatment with EP $(5 \mathrm{mmol} / \mathrm{L})$ at all time points examined $(n=6, p<0.01)$, suggesting $\mathrm{Ca}^{2+}$ chelation by EP in BV2 cells (see Figures 5A, B). To further confirm the ability of EP to chelate intracellular $\mathrm{Ca}^{2+}, \mathrm{EP}(1,2.5$ or $5 \mathrm{mmol} / \mathrm{L})$ was pretreated for $1 \mathrm{~h}$, medium was washed out, and cells were incubated with A23187 for $30 \mathrm{~min}$, and intracellular Fluo-4-positive fluorescence levels were measured at $1 \mathrm{~h}$ after A23187 treatment. As was expected, $\left[\mathrm{Ca}^{2+}\right]_{\mathrm{i}}$ levels were significantly reduced by EP pretreatment $(n=6, p<0.01)$ (Figures $5 \mathrm{C}, \mathrm{D})$, although the level of suppression observed was weaker than that observed for EP cotreatment at 1 and $5 \mathrm{mmol} / \mathrm{L}$. These results indicate that EP chelates $\mathrm{Ca}^{2+}$ in cytoplasm of BV2 cells and in media.

\section{NMDA-Induced HMGB 1 Secretion in Primary Cortical Cultures was Suppressed by $\mathrm{Ca}^{2+}$ Chelation}

It is well known that NMDA receptor activation induces long-lasting intracellular $\mathrm{Ca}^{2+}$ elevation in neurons (26). To demonstrate that $\mathrm{Ca}^{2+}$ chelation by EP is involved in the suppression of HMGB1 release in more physiological contexts, levels of HMGB1 were examined in media obtained from NMDA -treated (100 $\mu \mathrm{mol} / \mathrm{L}$ for $10 \mathrm{~min}$ or $50 \mu \mathrm{mol} / \mathrm{L}$ for $30 \mathrm{~min}$ ) primary cortical cultures in the presence or absence of EP. At $24 \mathrm{~h}$ after

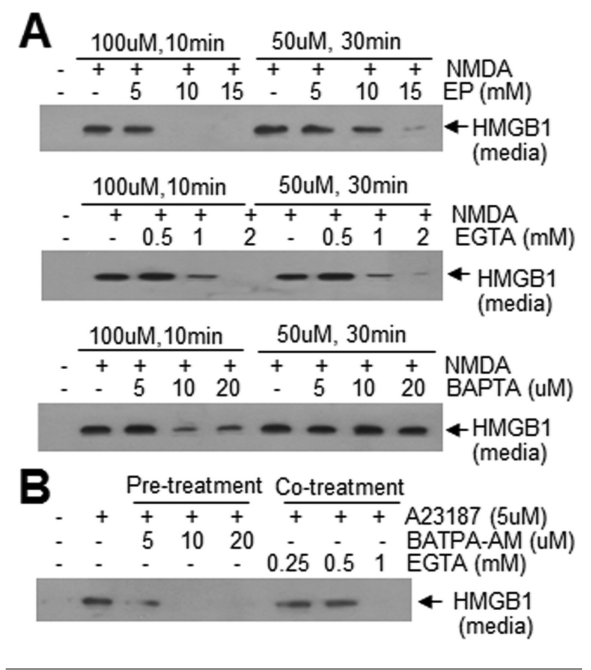

Figure 6. Inhibition of $\mathrm{HMGB} 1$ secretion by $\mathrm{Ca}^{2+}$ chelation in NMDA-treated primary cortical cultures and in A23187-treated BV2 cells. (A) Primary cortical cultures were cotreated with NMDA (100 $\mu \mathrm{mol} / \mathrm{L}$ for $10 \mathrm{~min}$ or $50 \mu \mathrm{mol} / \mathrm{L}$ for $30 \mathrm{~min}$ ) and EGTA (0.5, 1 or $2 \mathrm{mmol} / \mathrm{L})$ for $30 \mathrm{~min}$ or treated with NMDA after pretreating with BAPTA-AM (5, 10 or $20 \mu \mathrm{mol} / \mathrm{L})$ for $30 \mathrm{~min}$ and $\mathrm{HMGB} 1$ levels in culture media were estimated by immunoblotting at $24 \mathrm{~h}$ after NMDA treatment. (B) BV2 cells were cotreated with A23187 (5 $\mu \mathrm{mol} / \mathrm{L}$ ) and EGTA $(0.25,0.5$ or $1 \mathrm{mmol} / \mathrm{L})$ for $30 \mathrm{~min}$ or treated with NMDA after pretreating with BAPTA-AM (5, 10 or $20 \mu \mathrm{mol} / \mathrm{L})$ for $30 \mathrm{~min}$ and $\mathrm{HMGB} 1$ levels in culture media were estimated by immunoblotting at $24 \mathrm{~h}$ after A23187 treatment. Representative images from three independent experiments were presented.

NMDA treatment, HMGB1 accumulates in media of primary cortical cultures for both regimes (Figure 6A), which agrees with our previous report (27). HMGB1 accumulations in media were markedly inhibited by cotreating NMDA with EP in a dose-dependent manner (see Figure 6A). Similar inhibitions were observed after coor pretreating two well-known $\mathrm{Ca}^{2+}$ chelators, EGTA and BAPTA-acetoxymethyl ester (BAPTA-AM), respectively, with NMDA (see Figure 6A), suggesting that intracellular $\mathrm{Ca}^{2+}$ chelation suppressed NMDA-induced HMGB1 release in neurons. To further confirm the intracellular 

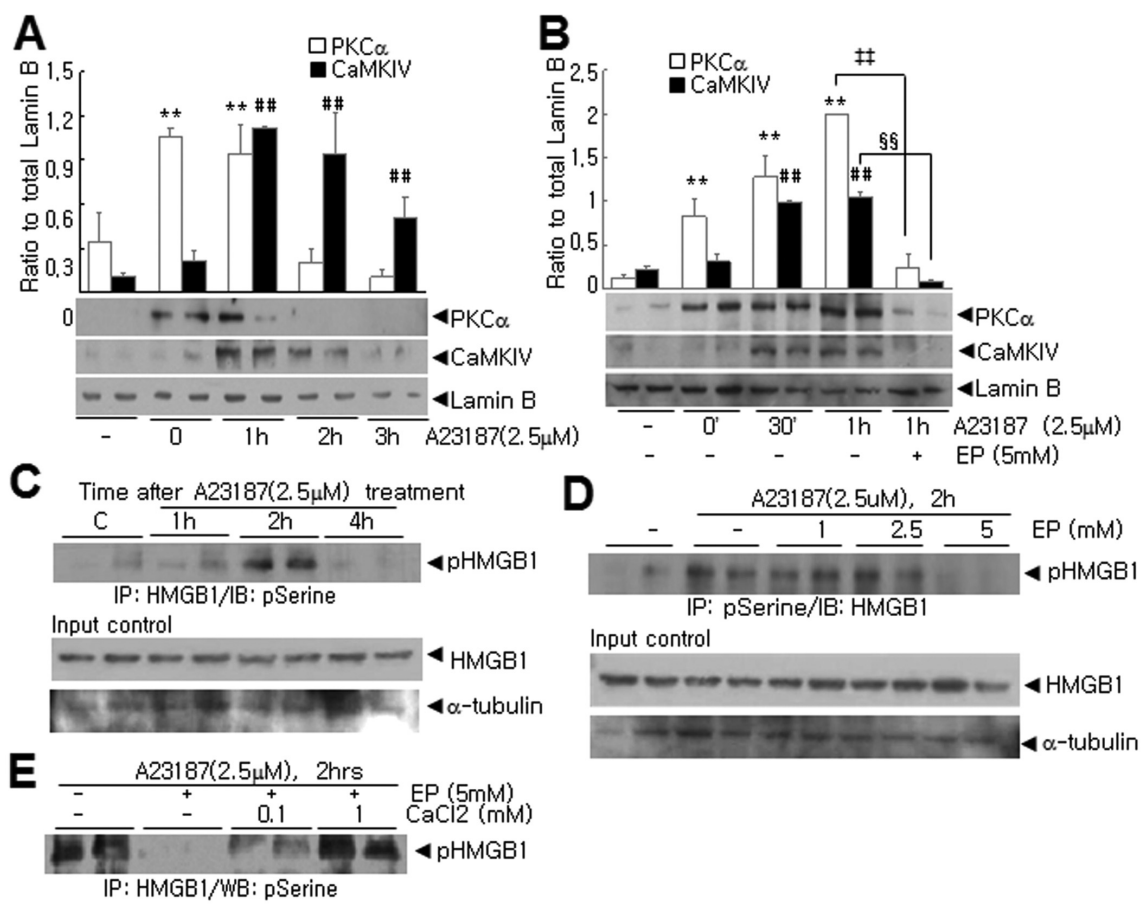

Figure 7. Reductions in $P K C \alpha$ - and CaMKIV-mediated HMGBI phosphorylations by EP in A23187-stimulated BV2 cells. (A) BV2 cells were treated with $2.5 \mu \mathrm{mol} / \mathrm{L}$ of A23187 (30 min) and nuclear levels of PCK $\alpha$ and CaMKIV were examined by immunoblotting at 1, 2, or $3 \mathrm{~h}$ after A23187 treatment. (B) BV2 cells were treated with $2.5 \mu \mathrm{mol} / \mathrm{L}$ of A23187 (30 min) with or without $5 \mathrm{mmol} / \mathrm{L}$ EP and nuclear levels of PCK $\alpha$ and CaMKIV were examined by immunoblotting at $30 \mathrm{~min}$ or $1 \mathrm{~h}$ after A23187 treatment. (C) Total cell lysates were collected at 1,2 or $4 \mathrm{~h}$ after $\mathrm{A} 23187$ treatment ( $2.5 \mu \mathrm{mol} / \mathrm{L}, 30 \mathrm{~min}$ ), immunoprecipitated for HMGBI, and then immunoblotted with anti-phospho-Ser antibody. (D) Total cell lysates were collected at $2 \mathrm{~h}$ after $\mathrm{A} 23187$ treatment $(2.5 \mu \mathrm{mol} / \mathrm{L}, 30 \mathrm{~min})$ in the presence of EP $(1,2.5$ or $5 \mathrm{mmol} / \mathrm{L}$ ), immunoprecipitated for HMGBl, and then immunoblotted with anti-phosphoSer antibody. Amounts of input protein before immunoprecipitation were estimated by immunoblotting with anti-HMGB1 and anti- $\alpha$-tubulin antibodies. (E) BV2 cells were treated with $2.5 \mu \mathrm{mol} / \mathrm{L}$ of $\mathrm{A} 23187$ and $5 \mathrm{mmol} / \mathrm{L} \mathrm{EP}$ with 0.1 or $1 \mathrm{mmol} / \mathrm{L} \mathrm{of} \mathrm{CaCl}_{2}$ for $30 \mathrm{~min}$. Lysates were collected $2 \mathrm{~h}$ later, immunoprecipitated for $\mathrm{HMGBI}$, and immunoblotted with anti-pSer antibody. Representative images from four independent experiments are presented (C-E) and data are presented as mean $\pm \operatorname{SEM}(n=4)$. One-way ANOVA, Newman-Keuls post hoc test. ${ }^{* *}$ and ${ }^{\# \#}$, difference from Con at $p<0.01$; ${ }^{\ddagger \ddagger}$ and ${ }^{\S \S}$, differences between indicated group at $p<0.05$ and $p<0.01$, respectively.

$\mathrm{Ca}^{2+}$-chelation-mediated suppression of HMGB1 release, HMGB1 levels in media were examined after treating cells with A23187 in the presence or absence BAPTA-AM and EGTA. HMGB1 accumulations were suppressed significantly when BV2 cells were pretreated with BAPTA-AM $(5,1020 \mu \mathrm{mol} / \mathrm{L})$ or cotreated with EGTA (1 mmol/L) (Figure 6B). These results indicate that intracellular $\mathrm{Ca}^{2+}$ chelation suppressed HMGB1 release in neurons and in glial cells.

\section{EP Suppressed A23187-Induced HMGB 1 Phosphorylation by Inhibiting the Activations of $\mathrm{Ca}^{2+}$-Mediated Kinases}

When BV2 cells were treated with A23187 (2.5 umol/L, $30 \mathrm{~min})$, nuclear levels of PKC $\alpha$ and CaMKIV increased immediately and remained increased in nuclei at 1 or $2 \mathrm{~h}$ after A23187 treatment, respectively, and then decreased (Figure 7A), indicating $\mathrm{Ca}^{2+}$-mediated activations of PKC $\alpha$ and CaMKIV in BV2 cells. However, cotreatment of EP (5 mmol/L) and A23187 (2.5 $\mu \mathrm{mol} / \mathrm{L}$, $30 \mathrm{~min}$ ) significantly suppressed the nuclear translocations of PKC $\alpha$ and CaMKIV observed after $1 \mathrm{~h}$ of A23187 treatment (Figure 7B). Furthermore, HMGB1 phosphorylation at its serine residues, which began to increase after $1 \mathrm{~h}$ of A23187 treatment and peaked at $2 \mathrm{~h}$ (Figure 7C), was markedly reduced by EP cotreatment in a dose-dependent manner (Figure 7D). Amounts of the precipitated proteins and input control were even in each lane, as evidenced by immunoblotting with anti-HMGB1 and anti$\alpha$-tubulin antibody (Figures 7C, D). Importantly, the addition of 0.1 or $1 \mathrm{mmol} / \mathrm{L}$ $\mathrm{CaCl}_{2}$ reversed the EP-mediated suppression of HMGB1 phosphorylation in A23187-treated cells, and this suppression was completely recovered by $1 \mathrm{mmol} / \mathrm{L} \mathrm{CaCl}_{2}$ (Figure 7E). Together these results indicate that EP suppresses the $\mathrm{Ca}^{2+}$-mediated activations of $P K C \alpha$ and CaMKIV and the phosphorylation of HMGB1.

\section{DISCUSSION}

Accumulating evidence indicates that the suppression of HMGB1 secretion by EP contributes to the antiinflammatory effect of EP. In mice with established endotoxemia, sepsis and murine colitis, EP reduced circulating levels of HMGB1 and significantly prevented lethality $(14,16)$ and in mice with LPS-induced acute lung injury, EP also significantly suppressed HMGB1 release and reduced lung permeability indices and improved survival (28). Recently, we also reported the suppression of HMGB1 phosphorylation and release by EP in BV2 cells and the suppression of HMGB1 release by EP in the postischemic brain (18). In addition to the suppression of HMGB1 secretion, EP has been reported to inhibit HMGB1 expression in traumatic brain injury (7) and in myocardial ischemia/reperfusion injury models (2). Accordingly, it appears that EP might provide a therapeutic means of ameliorating inflammatory responses by suppressing HMGB1 expression and secretion. To the best of our 
knowledge, this is the first report to propose that $\mathrm{Ca}^{2+}$ chelation by EP underlies the inhibition of HMGB1 secretion by EP.

Regarding the importance of $\mathrm{Ca}^{2+}$ in HMGB1 release, recent studies have reported that HMGB1 release can be induced by A23187 in murine hepatocytes and in RAW264.7 cells and that this release is reduced by BAPTA $(23,29)$. In addition, HMGB1 release induced by $\mathrm{H}_{2} \mathrm{O}_{2}$ or hypoxia in hepatocytes also was found to be suppressed by the chelation of $\mathrm{Ca}^{2+}$ by BAPTA, thus indicating that $\mathrm{Ca}^{2+}$ plays a critical role in oxidative stress-induced HMGB1 release probably by modulating CaMK (29). In the present study, we also showed HMGB1 release induced by A23187 in BV2 cells or by NMDA treatment in primary cortical cultures is suppressed by BAPTA and EGTA (Figure 6), demonstrating a crucial role of $\mathrm{Ca}^{2+}$ in HMGB1 release under various contexts and in various cells. Moreover, we demonstrated that A23187 induced intracellular $\mathrm{Ca}^{2+}$ increase with no concomitant cell death or activation (Figure 3), further confirming a direct role of $\mathrm{Ca}^{2+}$ in HMGB1 secretion independent of cell death or activation. In addition to modulating $\mathrm{Ca}^{2+}$-dependent enzymes involved in HMGB1 nuclear-cytoplasmic shuttling, intracellular $\mathrm{Ca}^{2+}$ plays a variety of roles which might be related to HMGB1 release. For example, secretory granules and/or lysosomes containing HMGB1 localized in cytoplasm were shown to be exocytosed from monocytes via $\mathrm{Ca}^{2+}$-regulated secretory pathway (30). Moreover, in the absence of $\mathrm{Ca}^{2+}$, the DNA binding properties of HMGB1, for which the C-terminal tail of HMGB1 plays an important role, were enhanced $(31,32)$, which suggested that $\mathrm{Ca}^{2+}$ plays a critical role in the interaction between HMGB1 and DNA and that $\mathrm{Ca}^{2+}$ probably affects, at least indirectly, the subcellular localization of HMGB1. These reports highlight the importance of $\mathrm{Ca}^{2+}$ signaling in translocation of HMGB1, and further support the possibility that $\mathrm{Ca}^{2+}$ chelation provides an important means of inhibiting HMGB1 secretion. However, in terms of the nuclear to cyto- plasmic translocation, the acetylation (33) and the redox modification of the cysteine residue (34) of HMGB1 also have been reported to be involved and we cannot exclude the possible roles of these modifications in HMGB1 secretion.

Considering the crucial roles played by metal ions as cofactors or enzyme modulators, $\mathrm{Ca}^{2+}$ chelation by EP might provide an important means of modulating cell death and survival under various pathological conditions. In the brain, free intracellular $\mathrm{Ca}^{2+}$ subserves complex roles as the main second messenger. Under pathological conditions of the brain, an intracellular free $\mathrm{Ca}^{2+}$ surge triggers various downstream neurotoxic cascades via the activations of various enzymes, such as calpains, proteases and endonucleases (35), and these early events result in free radical excess, cell swelling, DNA fragmentation and cytoskeletal breakdown, leading to apoptotic and/or necrotic cell death (36). Therefore, it can be postulated that in addition to the inhibition of HMGB1 release, various protective mechanisms emanating from $\mathrm{Ca}^{2+}$ chelation by EP contribute to its protective effects. Therefore, the robust neuroprotective effect of EP in the postischemic (3) and in the postepileptic brain (4) could be due to a combination of its antiinflammatory, antioxidative and antiapoptotic effects, wherein the suppression of HMGB1 release contributes to its antiinflammatory effect.

\section{CONCLUSION Q4}

Although our fluorometric study showed direct chelation of $\mathrm{Ca}^{2+}$ by EP (Figure 2), further studies are necessary to identify the binding site(s) involved and the mode of interaction. Regarding this, Sims et al. (37) proposed a mechanism whereby two ethyl pyruvate molecules are stabilized by one calcium ion. In addition, other molecular mechanisms possibly modulating intracellular $\mathrm{Ca}^{2+}$ levels, for example, blocking $\mathrm{Ca}^{2+}$ channel, need to be studied. However, we speculate that direct chelation plays a crucial role compared with $\mathrm{Ca}^{2+}$ channel blocking, if any, since A23187-induced intracellular calcium increase is not a $\mathrm{Ca}^{2+}$ channel-mediated phenomenon and, furthermore, intracellular $\mathrm{Ca}^{2+} \mathrm{lev}$ els were reduced significantly by EP posttreatment $1 \mathrm{~h}$ after A23187 treatment (data not shown). However, we cannot completely exclude this possibility at this moment and future studies are required.

\section{ACKNOWLEDGMENT}

This research was supported by grants from the Mid-Career Researcher Program (grant no. 2012-013195) and the Global Research Network (grant no. 220-2011-1E00027) of the Korean National Research Foundation (NRF) to J-K Lee.

\section{DISCLOSURE}

The authors declare that they have no competing interests as defined by Molecular Medicine, or other interests that might be perceived to influence the results and discussion reported in this paper.

\section{REFERENCES}

1. Venkataraman R, Kellum JA, Song M, Fink MP. (2002) Resuscitation with Ringer's ethyl pyruvate solution prolongs survival and modulates plasma cytokine and nitrite/nitrate concentrations in a rat model of lipopolysaccharideinduced shock. Shock. 18:507-12.

2. Woo YJ, et al. (2004) Ethyl pyruvate preserves cardiac function and attenuates oxidative injury after prolonged myocardial ischemia. J. Thorac. Cardiovasc. Surg. 127:1262-9

3. Yu YM, et al. (2005) Inhibition of the cerebral ischemic injury by ethyl pyruvate with a wide therapeutic window. Stroke. 26:2238-43.

4. Cho IH, et al. (2006) Ethyl pyruvate attenuates kainic acid-induced neuronal cell death in the mouse hippocampus. J. Neurosci. Res. 84:1505-11.

5. Yang ZY, et al. (2008) Delayed ethyl pyruvate therapy attenuates experimental severe acute pancreatitis via reduced serum high mobility group box 1 levels in rats. World J. Gastroenterol. 14:4546-50.

6. Wang Q, et al. (2009) Ethyl pyruvate attenuates spinal cord ischemic injury with a wide therapeutic window through inhibiting high-mobility group box 1 release in rabbits. Anesthesiology. 110:1279-86.

7. Su X, et al. (2011) Beneficial effect of ethyl pyruvate through inhibiting high-mobility group box1 expression and TLR/NF- $\mathrm{KB}$ pathway after traumatic brain injury in the rat. Mediators Inflamm. 2011:807142.

8. Song M, et al. (2004) Evidence that glutathione 
depletion is a mechanism responsible for the anti-inflammatory effects of ethyl pyruvate in cultured lipopolysaccharide-stimulated RAW 264.7 cells. J. Pharmacol. Exp. Ther. 308:307-16.

9. Han Y, et al. (2005) Ethyl pyruvate inhibits nuclear factor-kappaB-dependent signaling by directly targeting p65. J. Pharmacol. Exp. Ther. 312:1097-05.

10. Yang R, et al. (2002) Ethyl pyruvate modulates inflammatory gene expression in mice subjected to hemorrhagic shock. Am. J. Physiol. Gastrointest. Liver Physiol. 283:G212-21.

11. Yang R, et al. (2004) Ethyl pyruvate reduces liver injury in a murine model of extrahepatic cholestasis. Shock. 22:369-75.

12. Kim HS, et al. (2008) Ethyl pyruvate has an antiinflammatory effect by inhibiting ROS-dependent STAT signaling in activated microglia. Free Radic. Biol. Med. 45:950-63.

13. Kim SW, et al. (2013) Up-down regulation of HO1 and iNOS gene expressions by ethyl pyruvate via recruiting p300 to Nrf2 and depriving It from p65. Free Radic. Biol. Med. 65:468-76.

14. Ulloa L, et al. (2002) Ethyl pyruvate prevents lethality in mice with established lethal sepsis and systemic inflammation. Proc. Natl. Acad. Sci. U.S.A. 99:12351-6.

15. Chung KY, et al. (2008) The role of high-mobility group box-1 in renal ischemia and reperfusion injury and the effect of ethyl pyruvate. Transplant Proc. 40:2136-8.

16. Davé SH, et al. (2009) Ethyl pyruvate decreases HMGB1 release and ameliorates murine colitis. J. Leukoc. Biol. 86:633-43.

17. Liang X, et al. (2009) Ethyl pyruvate administration inhibits hepatic tumor growth. J. Leukoc. Biol. 86:599-607.

18. Shin JH, et al. (2014) Ethyl pyruvate inhibits HMGB1 phosphorylation and secretion in activated microglia and in the postischemic brain. Neurosci. Lett. 558:159-63

19. Scaffidi $P$, et al. (2002) Release of chromatin protein HMGB1 by necrotic cells triggers inflammation. Nature. 418:191-5.

20. Bianchi ME, et al. (2007) High-mobility group box 1 (HMGB1) protein at the crossroads between innate and adaptive immunity. Immunol. Rev. 220:35-46.

21. Youn JH, et al. (2006) Nucleocytoplasmic shuttling of HMGB1 is regulated by phosphorylation that redirects it toward secretion. J. Immunol. 177:7889-97.

22. Zhang X, et al. (2008) Calcium/calmodulin-dependent protein kinase (CaMK) IV mediates nucleocytoplasmic shuttling and release of HMGB1 during lipopolysaccharide stimulation of macrophages. J. Immunol. 182:5015-23.

23. Oh YJ, et al. (2009) HMGB1 is phosphorylated by classical protein kinase $\mathrm{c}$ and is secreted by a calcium-dependent mechanism. J. Immunol. 182:5800-9.

24. Committee for the Update of the Guide for the Care and Use of Laboratory Animals, Institute for Laboratory Animal Research, Division on Earth and Life Studies, National Research Council of the National Academies. (2011) Guide for the Care and Use of Laboratory Animals. 8th edition. Washington (DC): National Academies Press.

25. Kim SW, et al. (2011) Robust protective effects of a novel multimodal neuroprotectant oxopropanoyloxy benzoic acid (a salicylic acid/ pyruvate ester) in the postischemic brain. Mol. Pharmacol. 79:220-8

26. Connor JA, et al. (1988) Sustained dendritic gradients of $\mathrm{Ca} 2+$ induced by excitatory amino acids in CA1 hippocampal neurons. Science. 240:649-53.

27. Kim SW, et al. (2011) Extracellular HMGB1 released by NMDA treatment confers neuronal apoptosis via RAGE-p38 MAPK/ERK signaling pathway. Neurotox Res. 20:159-69.

28. Shang GH, et al. (2009) Ethyl pyruvate reduces mortality in an endotoxin-induced severe acute lung injury mouse model. Respir. Res. 10:91.

29. Tsung A, et al. (2007) HMGB1 release induced by ischemia involves Toll-like receptor 4 dependent reactive oxygen species production and calciummediated signaling. J. Exp. Med. 204:2913-23.

30. Gardella S, et al. (2002) The nuclear protein HMGB1 is secreted by monocytes via a non-classical, vesicle-mediated secretory pathway. EMBO Rep. 3:995-1001.

31. Stros M, et al. (1990) Calcium modulates the binding of high-mobility-group protein 1 to DNA. Biochem. Int. 21:891-9

32. Stros M, et al. (1994) Calcium binding to HMG1 protein induces DNA looping by the HMG-box domains. FEBS Lett. 344:201-6.

33. Bonaldi T, et al. (2003) Monocytic cells hyperacetylate chromatin protein HMGB1 to redirect it towards secretion. EMBO J. 22:5551-60.

34. Hoppe G, et al. (2006) Molecular basis for the redox control of nuclear transport of the structural chromatin protein Hmgb1. Exp. Cell Res. 312:3526-38.

35. Szydlowska K, et al. (2010) Calcium, ischemia and excitotoxicity. Cell Calcium. 47:122-9.

36. Orrenius S, et al. (2003) Regulation of cell death: the calcium-apoptosis link. Nat. Rev. Mol. Cell. Biol. 4:552-65.

37. Sims CA, et al. (2001) Ringer's ethyl pyruvate solution ameliorates ischemia/reperfusion-induced intestinal mucosal injury in rats. Crit. Care Med. 29:1513-8. 